\title{
ЛИЧНОСТНАЯ УНИКАЛЬНОСТЬ КЛИЕНТА КАК ОСНОВА ДЛЯ ТЕРАПИИ
}

\begin{abstract}
Аннотация. Автор статьи, на основе разработанной им личностно-ориентированной концепции счастья (ЛОКС) и ряда известных психологических теорий, представляет теоретическое обоснование проекта новой методики работы психолога с клиентом - терапии Личностной Уникальностью (ЛУТ). Осознание (конструирование) клиентом собственной «идеальной» части и контакт с ней позволяют уменьшить повреждающее воздействие внешних стрессов и жизненных неудач. Указаны возможности продуктивного взаимодействия ЛУТ с духовными и религиозными практиками.
\end{abstract}

Ключевые слова: психология, личностная уникальность, самореализация, счастье, эвдемония, терапия, личностно-ориентированная конщепщия счастья, ЛОКС, ЛУТ, психология счастья.

Что пользы человеку, если он завоюет весь мир, но потеряет себя? Иисус Христос

\section{Введение}

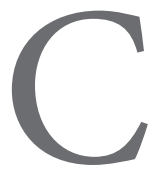

овременная психотерапия в настоящее время насчитывает свыше 400 систем и методов ${ }^{1}$. Основываясь на разработанной нами в 2006-2012 гг. Личностно-ориентированной концепции счастья (ЛОКС), мы решили предложить вниманию читателя проект психотерапии и самотерапии, в ходе которой клиент осознает собственную Личностную Уникальность (ЛУ) в качестве «идеальной» части, определяющей его жизненное предназначение, что служит защитой от внешнего дистресса.

Еще древнегреческий философ Сократ, один из основателей эвдемонической традиции, основанной на реализации человеком своего внутреннего потенциала, видел суть любви в ее устремленности к высшим ценностям, главной среди которых является «дэймон»внутренний дух индивида, его прирожденное совершенство ${ }^{2}$.

Обзор и проработка понятий, аналогичных выделенному конструкту («самость», «личностный потенциал», «истинное Я» и др.), осуществлены в наших по-

1 Норкросс Дж., Прохазка Дж. Системы психотерапии. М.: Прайм-ЕВРОЗНАК, 2007. С. 15.

2 Norton D.L. Personal Destinies. Princeton: Princeton University Press, 1976. C. X. следних монографиях ${ }^{3}$. Некоторые из вышеупомянутых терминов связываются авторами с представлением о самоактуализации личности в соответствующей активности ${ }^{4}$, другие - с понятием глубинного центра, места тишины и спокойствия ${ }^{5}$, бессознательной самости, являющейся средоточием высших человеческих сил 6 . В связи с этим нам показалось логичным и обоснованным включить подобные «ресурсные» представления в практику работы - особенно с высокообразованными клиентами, эрудированными в области психологии.

\section{Личностная Уникальность: краткий сравнительный анализ}

Конструкт Личностной Уникальности существенно отличается от «идеального Я», - понятия, введенного в употребление К. Роджерсом ${ }^{7}$. Последний термин обозначает то, кем человек хотел бы стать,

\footnotetext{
3 Левит Л.3. Личностно-ориентированная концепция счастья: жизнь во имя себя. Минск: Изд-во «А.Н. Вараксин», 2011. 112 с.; Левит Л.З. ЛОКС: между Фрейдом, Юнгом и Маслоу. Минск: Изд-во «А.Н. Вараксин», 2012. 120 с.

4 Маслоу А. Мотивация и личность. 3-е изд. СПб.: Питер, 2009. 352 с.; Роджерс К. Взгляд на психотерапию: становление человека. М.: Универс, 1994. 480 с.

5 Ассаджиоли Р. Психосинтез. М.: Психотерапия, 2008. 384 с.

6 Lazarus R.S. The Lazarus Manifesto for Positive Psychology and Psychology in General // Psychological Inquiry. 2003. Vol. 14. № 2. P. 173-189.

Роджерс К. Взгляд на психотерапию: становление человека. М.: Универс, 1994. 480 с.
} 


\section{Психология развития}

но пока не стал. Что касается ЛУ, которая во многом аналогична древнегреческому «дэймону», врожденному внутреннему духу человека, то она уже имеется в психике, в ее бессознательной части. Задача индивида заключается в том, чтобы обнаружить свою Личностную Уникальность и жить в согласии с ней, в полной мере реализовывая древний принцип: «Познай себя, и стань тем, кто ты есть» ${ }^{8}$. Поэтому ЛУ в отличие от «идеального Я» не порождает непроходимую пропасть между желаемым и действительным: искомые уникальные предпосылки присутствуют в человеке от рождения - задачей становится их обнаружение и продуктивная актуализация.

Разумеется, Личностная Уникальность не имеет ничего общего с фрейдовским «Сверх Я», поскольку обозначает скорее креативные и ресурсные возможности человека, чем его способность соответствовать общественным требованиям и нормам. Мы подчеркиваем данное очевидное для специалистов различие лишь из-за некоторой схожести в звучании абсолютно разных конструктов.

\section{Терапия Личностной Уникальностью}

Наша многолетняя психологическая практика показала, что выявление и контакт индивида с лучщей частью себя, своим «внутренним сокровищем», которое всегда остаётся с человеком, позволяет ему легче пережить периоды стрессов и жизненных кризисов ${ }^{9}$. Отметим, что еще Л.Н. Толстой в своей «Исповеди» указал, что для выхода из кризиса зачастую необходимо обретение новых духовных ценностей.

В этом смысле важно затронуть выявленную 3. Фрейдом сублимацию, при которой происходит перенаправление энергии на более высокую деятельность, что интенсифицирует внутренние процессы и тем самым позволяет приобрести определенную независимость от влияний внешнего мира. В этом случае, пишет 3. Фрейд, «судьба не в состоянии нанести большой вред» ${ }^{10}$.

Практически любой человек может вспомнить, как в тяжелые периоды в какой-то одной области (например, в работе), он «с головой» уходил во что-то другое, не затронутое кризисом - спорт, хобби или семейную жизнь, и таким образом находил ресурсы, чтобы пере-

\footnotetext{
8 Norton D.L. Personal Destinies. Princeton: Princeton University Press, 1976. 400 p.

9 Левит Л.З. ЛОКС: между Фрейдом, Юнгом и Маслоу. Минск: Изд-во «А.Н. Вараксин», 2012. С. 82.

10 Фрейд 3. Неудобства культуры. СПб.: Азбука-классика, 2010. С. 31
}

жить неприятности и справиться с ними. В этом смысле Личностная Уникальность человека предоставляет наиболее надежную опору по двум причинам. Во-первых, это лучшая, идеальная часть личности, поэтому контакт с ней наиболее плодотворен в тяжелые минуты. Вовторых, ЛУ находится внутри человека, дана ему от природы, а значит, она неуязвима, поскольку никакой внешний кризис не способен ее затронуть.

Если у индивида уже сформировалось внутреннее ощущение собственной Личностной Уникальности, то оно как раз и будет особенно («по контрасту») усиливаться в периоды неприятностей, связанных с внешним миром. Тем самым, у человека всегда будет возможность укрыться в уютном «убежище» и восстановить свое душевное равновесие.

Поэтому и приведенную в начале статьи цитату можно трактовать «от обратного»: индивиду ничего не страшно во внешнем мире, если он не потерял себя. Человек не завоевал мир, но и мир не сможет «завоевать» духовную сущность человека. В худшем случае, у индивида могут все отобрать, но никто не способен отнять у него Личностную Уникальность - его истинную драгоценность. Так что еще один полезный сопутствующий результат обучения ЛУ-терапии (ЛУТ) постепенное возникновение у клиента поистине буддистской «непривязанности» к повседневной суете. Вместо лихорадочной погони за все новыми удовольствиями (в итоге ведущей к потере себя) человек учится больше ценить то, что у него уже есть (свою Личностную Уникальность в том числе), что уменьшает либо полностью исключает невротическое переживание разрыва между желаемым и действительным. В последнем случае конструкт Личностной Уникальности, «идеальной» части индивида, находится как раз посередине между его далекими идеалами и более скромными наличными возможностями, и способен, таким образом, выступать в качестве связующего звена, «мостика» между первыми и вторыми. Это позволяет невротическому клиенту увидеть более зримый ориентир для конкретных действий по сравнению с несбыточными мечтами и грандиозными фантазиями.

Как, очевидно, заметил внимательный читатель, ЛУТ целесообразно использовать, когда индивид не способен изменить неблагоприятную «внешнюю» ситуацию, поэтому лучшим способом будет принять случившееся и примириться с ним. Концентрация внимания на сохранившихся внутренних возможностях, контакт со своей «идеальной частью» помогают процессу «самоутешения» и заживления ран: «Сейчас мне плохо, тяжело, но моя Личностная Уникальность по-прежнему со мной. В будущем я смогу ее реализовать и сделать свою жизнь счастливее». С нашей точки 


\section{Психология и психотехника 6(57) • 2013}

зрения, подобная фокусировка позволяет запустить и облегчить процесс коупинга, в ходе которого должен произойти постепенный «выход» из негативных переживаний к позитивным аспектам существования ${ }^{11}$. Конструкт Личностной Уникальности является в данном случае (возможно, единственным) положительным противовесом неприятностям, приходящим из внешнего мира, основой для будущих коупинг-процессов. Поскольку клиенту в начале травмирующего события сложно (если вообе возможно) искать позитивные аспекты в случившейся с ним трагедии, он может временно обратиться к своему внутреннему идеалу, сохраняя тем самым относительное психическое равновесие и силы для борьбы с трудностями. Баланс, борьба и диалектическое взаимодействие «хорошего» и «плохого», «добра» и «зла», о котором писал Р. Лазарус, противопоставляя реальное восприятие жизни усеченному позитивно-психологическому подходу ${ }^{12}$, как раз и создается в противостоянии «идеальной» ЛУ субъекта внешним неприятностям, которые на него обрушились. Виртуальный счет между «плохим» (имеющаяся проблема) и «хорошим» (собственная ЛУ) становится «равным». Клиент, обращаясь к своей Личностной Уникальности, получает возможность определенного дистанцирования в отношении негативных переживаний.

Наша точка зрения может быть подтверждена не только собственной профессиональной деятельностью, но и известными всем историческими аналогиями, когда притесняемые и жестоко преследуемые меньшинства (в частности, евреи) находили внутренние силы для борьбы за выживание и сохраняли самоуважение благодаря религиозному чувству «избранности», «особости». В этом смысле внутреннее «сокровище» Личностной Уникальности предельно компактно - его всегда можно «взять с собой». Кроме того, оно невидимо для окружающих, а потому не может стать объектом их (недружелюбных) действий.

Пациент в процессе психотерапии учится конструировать, осознавать, «слушать» свою идеальную часть и входить с ней в контакт, обогащаясь мудростью и психологическими ресурсами, что меняет фокусировку с «внешнего и плохого» на «внутреннее и хорошее». Клиент постепенно понимает, что главные «сокровища» находятся у него внутри, а не в материальном мире. Туда же, внутрь, открывается и «дверь

11 Lazarus R.S. The Lazarus Manifesto for Positive Psychology and Psychology in General // Psychological Inquiry. 2003. Vol. 14. № 2. P. 173-189.

12 Lazarus R.S. The Lazarus Manifesto for Positive Psychology and Psychology in General// Psychological Inquiry. 2003. Vol. 14. № 2. P. 173-189. к счастью». Конструкт Личностной Уникальности служит в этом случае «маяком», побуждающей силой для внутреннего роста. Счастливое, полноценное существование достигается человеком, когда он живет в соответствии со своим «внутренним духом», а не внешней суетой.

Если индивид поначалу затрудняется в подробном описании ЛУ, он может представлять ее в виде метафоры, по принципу «как если бы» - например, в качестве источника внутреннего тепла. Подобные упражнения придают человеку дополнительные силы в развитии собственной индивидуальности, стабилизируют его самооценку и позволяют более оптимистично смотреть в будущее (поскольку в настоящем под рукой теперь всегда имеется «спасательный якорь»). Конструкт Личностной Уникальности является моделью того, что возможно внутри нас; он помогает ответить на вопросы: «Для каких жизненных целей и поступков я создан? Что я хочу и буду делать в жизни, чтобы прожить её осмысленно и счастливо?» Именно в этом заключается суть по-настоящему позитивной психологии и психотерапии. Отметим, что измерение «смысла» появляется в жизни субъекта лишь после понимания им глубинных слоев собственной индивидуальности.

Проецирование индивидом лучших качеств в Личностную Уникальность позволяет ему начать движение по «пути совершенства», перерастая свою зацикленность на повседневных житейских неурядицах. Клиенту предлагается почувствовать себя «героем» собственной жизни, находящимся на пути к счастью. Любой «правильный» для клиента образ жизни и поступки, позволяющие, помимо прочего, успешно справляться с имеющимися у него симптомами, теперь совершаются ради укрепления и последующей реализации собственной Личностной Уникальности («идеальные» поступки для усиления «идеальной» части). Любая активность индивида, направленная на «решение проблем», может интерпретироваться в качестве основы для будущей реализации ЛУ и являться, тем самым, поводом для гордости за себя и укрепления самооценки. Человек, достигший личностной зрелости и осознающий в себе уникальное Я, начинает в большей степени «учиться» у себя, нежели у других.

С нашей точки зрения, ЛУТ может быть успешно использована и с религиозными людьми, исповедующими духовные ценности. Отметим, что уже первые монахи-отшельники, практиковавшие работу с текстами Священного Писания, с помощью определенных психотехник развивали «внимание к себе» (просохе) в качестве одной из главных добродетелей ${ }^{13}$. Ранние

13 Армстронг К. Биография бога. М.: ЭКСМО, 2012. С. 137. 


\section{Психология развития}

школы христианства (вслед за древнегреческими философами Сократом, Платоном и Аристотелем) делали акцент на том, что «усия» (нередуцируемое «ядро» в психике индивида, подобное божественной сущности) имеется у каждого человека.

Рассматривая свою идеальную, духовную часть как «дыхание бога», верующий устанавливает и укрепляет связь с высшим существом через улучшение самого себя ${ }^{14}$. По определению, духовность и трансцендентность представляет собой соединение человека с тем, что «выше» его. Но как раз Личностная Уникальность человека прекрасно подходит на роль объекта духовных поисков и практик, поскольку является идеальной частью личности, стоящей над повседневной суетой. При этом она лоцируется внутри самого субъекта, а не вне его. В этом смысле «божественная сила» уже находится в человеке, и теперь ему остается лишь услышать этот внутренний голос и жить в согласии с ним, перерастая тем самым свою озабоченность житейскими проблемами.

Известно, что «религия помогает выстроить внутри себя мирную гавань, которая позволит творчески преодолевать жизненные скорби» ${ }^{15}$. С точки зрения ЛУТ, подобная «гавань» уже имеется внутри каждого человека, хотя она до поры и скрыта в его бессознательном. И для этого нет необходимости превращаться в «сверхчеловека» или пытаться «стать богом», чего, в частности, опасается К. Армстронг ${ }^{16}$.

Наиболее последовательный и нетривиально мыслящий адепт собственной ЛУ мог бы в экспериментальных целях попытаться создать некий вариант персональной «религии», в которой Личностная Уникальность могла бы рассматриваться в качестве конечного аналога «высшего разума». В этом случае при истолковании реальности на место понятию «бог» приходит понятие «ЛУ», например: «ЛУ подвергает меня испытаниям», «неисповедимы пути ЛУ» и т. д. Как и в традиционной религии, могут быть созданы специальные места, при посещении которых индивид ощущал бы свою Личностную Уникальность «с особой силой». Мы ни в коем случае не намерены пропагандировать подобную «экстремальную» возможность, а всего лишь хотим еще раз продемонстрировать широкий потенциал идей, имплицитно присутствующий в нашей системе.

14 Левит Л.3. Личностно-ориентированная концепция счастья: жизнь во имя себя. Минск: Изд-во «А.Н. Вараксин», 2011. C. 99-100.

15 Армстронг К. Биография бога. М.: ЭКСМО, 2012. С. 283.

16 Там же. С. 285.
Концепт Личностной Уникальности позволяет избежать традиционного противопоставления «коллективной духовности» и «индивидуального эгоизма». С одной стороны, ЛУ «индивидуальна», с другой, - «неэгоистична» и «духовна», поскольку представляет собой лучшую часть человеческой личности.

Вообще диапазон пациентов для применения ЛУТ кажется нам достаточно широким. Очевидно, методику в модифицированном виде можно применять даже с психотическими пациентами вне периода обострений. Так, например, можно обратить внимание клиента на то, что у него имеется не только «больная», но и «здоровая» часть личности, в которой могут быть скрыты важные ресурсы. Совместная с психотерапевтом работа по укреплению и расширению этой «лучшей» части позволит больному в будущем вести более счастливую жизнь.

\section{ЛУТ и нарииссизм}

Поверхностный взгляд может заметить некоторое сходство между постулатами ЛУ-терапии и нарциссическими проявлениями личности. ЛУТ не имеет отношения к нарциссизму, поскольку Личностная Уникальность - это не «весь я», а лишь одна моя (идеальная) часть, пока еще скрытая в бессознательном и требующая немалого труда с моей стороны для выявления и реализации. Поэтому у субъекта нет особой «гордости» перед окружающими, однако ему не требуется и их «восхищение». Тот, кто «полон собой», лишен нарциссической зависти по отношению к другим. Ради развития и реализации Личностной Уникальности индивиду следует прилагать усилия, работать над собой и вести этическую, «правильную» жизнь, чтобы осуществить свое индивидуальное предназначение.

Выражаясь метафорически, субъект может рассматривать самого себя как «слугу» при данной идеальной части, который должен всячески помогать ей, осуществляя тем самым и собственный личностный рост. Созданный (или осознанный) во внутреннем мире новый, идеальный конструкт отныне требует от клиента реальных конструктивных действий - «доказательств» своего существования. Иначе вера субъекта в наличие собственной Личностной Уникальности может пошатнуться либо исчезнуть вообще. Подобная напряженная деятельность, связанная с реализацией индивидом своего жизненного предназначения, не имеет ничего общего с нарциссическим высокомерием и самолюбованием, с беспочвенными фантазиями собственной грандиозности. Более того, ЛУТ, по-видимому, может оказаться полезной и для нарциссических личностей, нередко страдающих от внутренней пустоты 


\section{Психология и психотехника 6(57) • 2013}

и недостатка самоуважения ${ }^{17}$. Клиент получает новую возможность (возможность реализации собственного потенциала), внутреннюю точку опоры, которая дарит ему дополнительную надежду в трудную минуту, а в случае своего успешного воплощения в будущем заслуженное чувство самоуважения. Отметим, что еще до «внешней» самореализации индивид должен приложить «внутренние» усилия для того, чтобы обнаружить свою Личностную Уникальность и войти с ней в контакт, что, как видим, не имеет ничего общего с нарциссическими проявлениями.

Вопрос о том, что случится с нарциссической личностью, если ей все же удастся сформировать подобный внутренний конструкт без последующих попьток его внешней реализации - точнее, может ли данное новообразование, оставаясь «неиспользованным», усилить нарциссические проявления (в частности, грандиозные фантазии пациента), либо однозначно ослабит их - не может быть разрешен в рамках данной статьи и нуждается в дополнительном изучении. Многое в данной ситуации зависит от действий специалиста, побуждающего своего клиента (в том числе, с помощью домашних заданий) к полезной активности во внешнем мире «в соответствии со своей ЛУ». В то же время, очевидно, что при расстройствах, характеризующихся падением самооценки и потерей самоуважения (например, депрессивном или тревожном), ЛУТ способна быть полезной - по крайней мере, в качестве вспомогательного средства.

Клиенты, обучаясь приёмам ЛУ-терапии у психолога, в дальнейшем способны использовать их самостоятельно. Наиболее подходящими ситуациями для этого являются повышенная «агрессивность» окружающей среды, недостижение индивидом карьерных целей, всевозможные жизненные кризисы - все те обстоятельства, которые провоцируют у индивида «выученную беспомощность» и ощущение себя в качестве жертвы. Важно, чтобы приёмы самотерапии Личностной Уникальностью были направлены внутрь использовались для собственной защиты, а не для ответной агрессии.

\section{Практическая методика и обсуждение результатов}

Читатель, вероятно, заметил, что ЛУТ принесет оптимальный результат индивиду, уже знакомому с понятием «Личностная Уникальность» и способному находиться в контакте с соответствующими внутренними ощущения-

17 Мак-Вильямс Н. Психоаналитическая диагностика. М.: Класс, 2004. 480 с. ми. Поскольку подобного рода практические методики не были обнаружены, мы решили восполнить данный пробел. С этой целью мы разработали Эвдомонический Тренинг (ЭТ), основанный на классических и современных идеях эвдемонии - теории, описывающей полноценную и счастливую жизнь субъекта в соответствии со своим «внутренним духом». Тренинг состоит из небольшого объема теории и двадцати упражнений, проводимых автором в небольших группах. Цель ЭТ заключается в том, чтобы помочь каждому участнику войти в контакт со своей «идеальной» частью (ЛУ), своим «дэймоном», а также исследовать основные аспекты собственной жизни (работа, проведение досуга, состояние здоровья, взаимоотношения, прошлые выборы и будущие перспективы) с подобной точки зрения. Мы считаем, что подобного рода работа позволит индивиду и в будущем легче переносить жизненные дистрессы, поскольку тот всегда будет иметь под рукой надежную внутреннюю опору.

Приведем примеры разговорных упражнений из середины тренинга (прямая речь ведущего).

1. С точки зрения древнегреческих философов, человек, ведущий эвдемоническую жизнь, находящийся в контакте со своей Личностной Уникальностью, способен отличать «верные» желания от «неверных» (для него самого). Выраженное ощущение внутренней правоты в ситуации жизненного выбора показывает, что индивид опирается на свое «истинное Я». Могли бы вы привести собственные примеры подобного рода и рассказать о том, что при этом чувствовали?

2. Приведите примеры верных для вас целей; тех, что «лишь вы один» способны достичь и осуществить.

3. В каких жизненных ситуациях вы ощущаете, что живете «поперек себя», находясь тем самым в состоянии дисдэймонии, своего рода внутреннего конфликта?

Шесть занятий с экспериментальной группой проводились раз в неделю; продолжительность каждого составляла 4 астрономических часа.

В тренинге принимали участие 15 человек в возрасте 27-36 лет, 9 женщин и 6 мужчин, все с высшим образованием, не психологи.

Тренинг проводился в период 11.05. - 15.06.2011 г. На первом занятии (11 мая), а также спустя месяц после окончания последнего занятия (15 июля) проводилось обследование испытуемых с помощью разработанного автором опросника ЗУлУРЭГ ${ }^{18}$ с последующим сравнением полученных данных (табл. 1).

18 Левит Л.3. Личностно-ориентированная концепция счастья: жизнь во имя себя. Минск: Изд-во «А.Н. Вараксин», 2011. $112 \mathrm{c}$. 


\section{Психология развития}

Табтииа 1

Статистические результаты использования ЗУлУРЭГ до и после Эвдемонического Тренинга

\begin{tabular}{|c|c|c|c|c|}
\hline Шкала & Время & $\mathrm{m}$ & $\sigma$ & $\mathrm{p}$ \\
\hline \multirow{2}{*}{0} & До ЭТ & 2.73 & 1.16 & \multirow{2}{*}{0.007} \\
\hline & Месяц после Эт & 1.27 & 0.92 & \\
\hline \multirow{2}{*}{1} & До ЭТ & 11.9 & 1.51 & \multirow{2}{*}{0.004} \\
\hline & Месяц после ЭТ & 13.7 & 1.40 & \\
\hline \multirow{2}{*}{$2 a$} & До ЭТ & 33.1 & 5.18 & \multirow{2}{*}{0.005} \\
\hline & Месяц после ЭТ & 39.0 & 3.40 & \\
\hline \multirow{2}{*}{$2 b$} & До ЭТ & 12.6 & 2.82 & \multirow{2}{*}{0.003} \\
\hline & Месяц после ЭТ & 18.7 & 3.26 & \\
\hline \multirow{2}{*}{$2 c$} & До ЭТ & 10.0 & 2.93 & \multirow{2}{*}{0.002} \\
\hline & Месяц после ЭТ & 4.47 & 2.95 & \\
\hline \multirow{2}{*}{$3 a$} & До ЭТ & 13.8 & 1.66 & \multirow{2}{*}{0.084} \\
\hline & Месяц после ЭТ & 15.1 & 1.67 & \\
\hline \multirow{2}{*}{$3 b$} & До ЭТ & 10.1 & 2.58 & \multirow{2}{*}{0.001} \\
\hline & Месяц после ЭТ & 4.13 & 2.20 & \\
\hline \multirow{2}{*}{$3 c$} & До ЭТ & 7.33 & 1.23 & \multirow{2}{*}{0.006} \\
\hline & Месяц после ЭТ & 9.20 & 1.70 & \\
\hline
\end{tabular}

Примечание.

$\sigma-$ стандартное отклонение

$\mathrm{m}$ - среднестатистический показатель

p - уровень статистической значимости. Использовался критерий Вилкоксона (Wilcoxon Matched Pairs Test).

Результаты исследования демонстрируют существенный рост показателей, связанных с эвдемонической активностью индивида (шкала 2a «Разумный Эгоизм» и шкала $2 \mathrm{~b}$ «Личностная Уникальность»), a также сильное уменьшение шкалы 2c «Базовый Эгоизм». Таким образом, возможен достаточно быстрый переход субъекта к ощущению своего «идеального Я», своей Личностной Уникальности с последующей нарастающей самореализацией и ростом удовлетворенности собственной жизнью.

Краткосрочные результаты Эвдемонического Тренинга были обсуждены в интервью, завершающем исследование. Отчеты наших подопечных касались усилившейся способности полагаться на собственные силы, желания прокладывать уникальный жизненный путь, иметь более глубокие и насыщенные отношения с близкими людьми, искать своих «единомышленников» - людей близких по духу, вести более здоровый образ жизни. Ни один участник эксперимента не обнаружил за истёкший после ЭТ месяц какой-либо особенный «талант», хотя это и не являлось нашей целью. Но большинство из них стали тратить больше времени и сил на те виды активности, к которым они ощущали внутреннюю склонность, приобретая тем самым большее удовлетворение от своей «эвдемонической» жизни. Таким образом, имело место общее уменьшение и снижение значимости «низших» эгоистических компонентов в сочетании с качественной трансформацией «высших» во имя духовного роста и уникальной самореализации.

Сравнительная «легкость» и системный характер сдвига в сторону эвдемонической жизненной ориентации (во всяком случае, для практически здорового человека) косвенным образом поддерживают гуманистический постулат о (более-менее) «справедливом» распределении «даров природы» (врожденного личностного потенциала, либо, по крайней мере, его ощущения) среди людей. Подобные ощущения могут и должны быть использованы в процессе ЛУТ.

И наоборот, другие наши исследования, проведенные в апреле 2011г. в отделении неврозов десятой клинической больницы г. Минска с использованием опросника ЗУЛУРЭГ, показали, что пациенты с диагнозами «депрессия» и «тревожное расстройство» (что может быть ассоциировано с несчастьем), имели повышенные показатели шкалы «Базового Эгоизма» и сниженные показатели шкал «Здоровья» и «Личностной Уникальности» относительно контрольной группы здоровых испытуемых ${ }^{19}$.

Мы по-прежнему не можем утверждать наверняка, что каждый индивид от рождения обладает неким «даром» (Личностной Уникальностью, «дэймоном»), но, по крайней мере, мы теперь знаем, что данное ошущение может быть сравнительно быстро усилено у обычных взрослых людей.

Читателям, знакомым с нашими последними работами, известно, что оптимальная реализация зрелой Личностной Уникальности осуществляется с помощью высших форм эгоизма (а точнее - индивидуализма) субъекта. Мы не затрагиваем данный вопрос в настоящей статье только потому, что ее основная цель в ином - помочь человеку быстрее и успешнее справляться с неприятными неожиданностями, приходящими из внешнего мира.

Наши систематические исследования в области ЛУТ начались сравнительно недавно. В последующих работах, по мере накопления и обобщения материала, мы планируем дать большую детализацию теории, упражнений и рекомендаций в зависимости от специфических жалоб клиента и характера имеющихся у него проблем.

19 Там же. 


\section{Психология и психотехника 6(57) • 2013}

\section{Список литературь:}

1. Армстронг К. Биография бога. М.: ЭКСМО, 2012. 432 c.

2. Ассаджиоли Р. Психосинтез. М.: Психотерапия, 2008. 384 с.

3. Левит Л.3. Личностно-ориентированная концепция счастья: жизнь во имя себя. Минск: Изд-во «А.Н. Вараксин», 2011. 112 с.

4. Левит Л.3. ЛОКС: между Фрейдом, Юнгом и Маслоу. Минск: Изд-во «А.Н. Вараксин», 2012. 120 с.

5. Мак-Вильямс Н. Психоаналитическая диагностика. М.: Класс, 2004. 480 с.

6. Маслоу А. Мотивация и личность. 3-е изд. СПб.: Питер, 2009. 352 с.

7. Норкросс Дж., Прохазка Дж. Системы психотерапии. М.: Прайм-ЕВРОЗНАК, 2007. 384 с.

8. Роджерс К. Взгляд на психотерапию: становление человека. М.: Универс, 1994. 480 с.

9. Юнг К.Г. Синхрония: аказуальный объединяющий принцип. М.: АСТ, 2009. 352 c.

10. Lazarus R.S. The Lazarus Manifesto for Positive Psychology and Psychology in General // Psychological Inquiry. 2003. Vol. 14. № 2. P. 173-189.

11. Norton D.L. Personal Destinies. Princeton: Princeton University Press, 1976. 400 p.

\section{References (transliteration):}

1. Armstrong K. Biografiya boga. M.: EKSMO, 2012. $432 \mathrm{~s}$.

2. Assadzhioli R. Psikhosintez. M.: Psikhoterapiya, 2008. 384 s.

3. Levit L.Z. Lichnostno-orientirovannaya kontseptsiya schast'ya: zhizn' vo imya sebya. Minsk: Izd-vo «A.N. Varaksin», 2011. 112 s.

4. Levit L.Z. LOKS: mezhdu Freydom, Yungom i Maslou. Minsk: Izd-vo «A.N. Varaksin», 2012. 120 s.

5. Mak-Vilyams N. Psikhoanaliticheskaya diagnostika. M.: Klass, 2004. 480 s.

6. Maslou A. Motivatsiya i lichnost'. 3-e izd. SPb.: Piter, 2009. 352 s.

7. Norkross Dzh., Prokhazka Dzh. Sistemy psikhoterapii. M.: Praym-EVROZNAK, 2007. $384 \mathrm{s.}$

8. Rodzhers K. Vzglyad na psikhoterapiyu: stanovlenie cheloveka. M.: Univers, 1994. $480 \mathrm{~s}$.

9. Yung K.G. Sinkhroniya: akazual'nyy ob’edinyayushchiy printsip. M.: AST, 2009. 352 s.

10. Lazarus R.S. The Lazarus Manifesto for Positive Psychology and Psychology in General // Psychological Inquiry. 2003. Vol. 14. № 2. P. 173-189.

11. Norton D.L. Personal Destinies. Princeton: Princeton University Press, 1976. 400 p. 